Full length article

\title{
Determinants of effective action on workplace safety and health in global companies - The case of global network container terminal operators
}

\author{
David Walters *, Emma Wadsworth \\ Seafarers' International Research Centre, Cardiff University, United Kingdom
}

\section{A R T I C L E I N F O}

\section{Keywords:}

Container terminals

Occupational safety and health (OSH)

Global network terminal (GNT) operators

Multinational companies (MNCs)

Human resource management (HRM)

Determinants

\begin{abstract}
A B S T R A C T
Container terminals are critical nodes in the globalisation of trade. Many are operated by global companies with strong corporate rhetoric espousing zero tolerance of injury and ill-health. Yet operational practices often contribute to the intensification of work and outsourcing of labour; conditions associated with poor safety and health. Serious and fatal injuries and ill-health continue to occur in these terminals. With reference to the findings of a study of occupational safety and health (OSH) arrangements in terminals operated by four of the largest operators, key contextual determinants in the terminals' labour relations and regulatory environments that influence practice and outcomes are identified. The influences are compared in different national settings and, the paper finds, like multinational companies generally, global operators are obliged to adapt and reflect local contexts. In relation to OSH best practice, a critical influence is the way that local context acts to constrain and challenge business logics and interests. This acts to make 'best practice' more likely where companies are constrained in this way, regardless of the claims of their corporate rhetoric.
\end{abstract}

\section{Introduction}

Container terminals are important nodes in the transport of goods and their contribution to increasing speed and efficiency in this process, and facilitation of current patterns of global production and trade are widely recognised $[1,2]$. It is also widely acknowledged that this has occurred during a time of change in the organisation of ports internationally, with the emergence of a new generation of ports with changed patterns of ownership and operation. The result is a global network of nodes and hubs in 'super-highways' for maritime and land transport. The terminals that form a part of this network, are purpose built or substantially adapted for container transportation and prominent in dock work everywhere. Many are operated by large global companies that often also have other interests in transportation. For example, they often also own and operate some of the shipping lines that carry the containers as well as other logistics businesses [2]. They are involved in fierce competition to maintain their profit margins. The ways in which work and employment are organised in the terminals reflect the consequences of this business competitiveness and national economic policies are often bound up with its support. [1,2].

The key features of such organisation include substantial reduction in employment in ports as various forms of mechanisation, engineering and systems design render physical handling of goods substantially redundant, and the reorganisation of employment through substantial use of contractors.

It is often assumed that the safety and health of workers employed in these terminals has been improved by these changes [3]. However, there is little robust empirical data to support this assumption. For this reason, the study on which this paper draws, explored experiences of health and safety arrangements and their outcomes in container terminals operated by four of the largest Global Network Terminal (GNT) operators in different parts of the world. Findings from the study have been published in several recent accounts [4-6]. They provide evidence suggesting conditions of work in container terminals are neither as safe nor as healthy as is often assumed.

The aim of the present paper is not to detail these findings again, but to explore what they suggest are determinants of good practice in different national settings. It identifies parallels between its findings and those on the human resource management strategies of multi-national companies (MNCs) and uses these parallels, along with those found in the industrial relations and regulatory literatures, to help set the empirical findings of the research that are detailed in previous publications in the context of wider explanations of work relations and regulation. In addition, however, its discussion is situated in relation to

\footnotetext{
* Corresponding author.

E-mail address: waltersd@cardiff.ac.uk (D. Walters).
} 
analytical themes on governance and regulation and the determinants of compliance.

The paper first outlines the methods used in the study from which evidence is drawn and which examined OSH arrangements in terminals in Europe and the Asia-Pacific region. The original study used both qualitative and quantitative methods. Results obtained from a combination of these are employed in the present paper to support and enrich the development of its argument, which uses OSH experience to explore interplay in relations between strategies of global corporate management and those of the determinants of national practice. It briefly relates the findings of the study to the existing literature on safety and health in the industry, before analysing the role of contextual determinants of $\mathrm{OSH}$ arrangements. It focuses especially on differences seen in labour relations histories and regulation in the countries in which the terminals were located. Sets of determinants derived from both these contexts are found to be significant moderators of the $\mathrm{OSH}$ practice of the companies studied.

\section{Study methods}

The study adopted a mixed-methods approach to study container terminals in Europe and Asia-Pacific. Three of the four countries in which the terminals were found were high-income economies with, in which the strong labour market position of dockworkers had influenced well-developed regulatory scrutiny of OSH including, in one of the European countries, provision for occupational health and safety services. However, in all three countries, changes over recent years, had weakened the position of organised labour and the presence of regulatory inspection.

In the low-to middle income country in which the remainder of the terminals in the study were found, both regulation and the position of organised labour were far less well developed.

As detailed in previously published accounts, data were collected between 2014 and 2016 at the global/corporate and terminal levels [4, 5]. Semi-structured face-to-face interviews were used and OSH data supplied by the companies were also analysed. In each terminal OSH data on the experiences of the operational workforce were gathered through a questionnaire-based survey and semi-structured interviews with workers and their supervisors, managers and representatives [4].

Research instruments covered: the experience of arrangements for $\mathrm{OSH}$, and their outcomes; the operation of OSH management systems and practices, and arrangements for representing, consulting and involving workers in $\mathrm{OSH}$.

Nine terminals were studied and a sample of 1619 operational dockworkers completed a questionnaire. In addition, 162 were interviewed. Virtually all survey respondents were male (1505, 98\%; as there were relatively few women employed in operational activities), aged between 20 and 50. About two thirds of workers were directly employed, and most had been in their job for between one and 15 years. Most worked in roles involving crane and/or horizontal transport [4-6].

Qualitative findings were coded and themes analysed using NVIVO. Quantitative results were analysed using SPSS and Chi-square, ANOVA and binary backward stepwise logistic regression. They examined OSH management and its outcomes and compared them by creating composite measures of safety outcomes, health outcomes, OSH management arrangements and working conditions following an approach used in previous research on OSH management (e.g. van Stolk et al. [7]). Measures were also split at the median to allow comparison of those with high and low levels of each set of experiences.

Previously published findings focused on an analysis of OSH arrangements and their outcomes as they are understood by the workers who experience them [6]; and a further analysis of differences between workers' experience of OSH and that of corporate leaders and managers [5]; along with a study of differences in labour relations between a highand low-income country [8]. The present paper develops analysis of the determinants of this experience and especially the significance of interplay between global corporate influence and local determinants such as are found in regulatory and labour relations as well as in national administrative arrangements for OSH. To illustrate their effects graphically, it plots a measure of workers' OSH experiences against one of context. In brief, composite measures of workers' experiences of safety and health outcomes, working conditions and OSH management arrangements, in each terminal, were first summed [4,6]. Then four measures representing the contexts of these experiences were also summed for each terminal. They included: the percentage of the workforce not represented by an independent union; the percentage indirectly employed; a comparative estimate of the degree of devolution of port ownership along a 'continuum' from fully privatised to wholly in public ownership, (the former scoring highest); and a comparative estimate of the maturity of national OSH governance systems, again along a 'continuum' with higher scores indicating greater immaturity. Scores on both these measures were created for terminals situated in each of the four geographical regions studied. By averaging their respective terminal scores, combined composite measures of health and safety experiences in the terminals could be plotted against each of the contextual measures described above. The results of this exercise are seen in Fig. 2 which is discussed later in the paper.

\section{Occupational safety and health arrangements and outcomes in container terminals}

The effects of port transformation on the health, safety and wellbeing of dockworkers has been relatively little studied. Conventional wisdom might anticipate that OSH would be improved in comparison with past conditions. At first sight this appears the case, at least as far as injuries are concerned [3]. Company level aggregate injury data collected in the present study also showed a downward trend in many regions of the world. But as demonstrated in greater detail elsewhere, the comparability and quality of these data were severely limited by variations in reporting practices, making them unreliable [6].

Work related ill-health that is traditionally associated with dockwork, includes musculoskeletal disorders (MSD), whole body vibration effects, noise-induced hearing-loss and harmful accidental exposures to noxious chemical and biological agents. It is not clear from previous research the extent to which the current organisation of work container terminals contributes to the reduction of the incidence of these conditions. New forms of occupational ill-health might also arise from such work organisation. Here again, there has been relatively little study of this. One detailed study concerning such safety and health outcomes following the containerisation of an Italian port suggested that the employment and organisational changes that accompany containerisation may have created new risks, in particular the study finds psychosocial risk factors along with ergonomic risks that are qualitatively different from previous experiences to be of particular concern [9]. In other sectors OSH consequences associated with similar changes in the organisation of work and employment to those seen in container terminals are better-established. For example, establishments operating with a reduced and casualised workforce, with agency, contractor and directly employed workers engaged on the same worksite, are associated with increased vulnerability to accidents, injuries and ill-health [10-12]. Intensified production demands and tight delivery schedules, (common in the loading and unloading of ships), are further associated with increased psycho-social risks health. These are known to not only cause forms of work-related ill-health such as stress and fatigue, but to also lead to increased risks of incidents that may cause injury or even fatalities [10].

The self-reported experiences of harm among the respondents in the present study showed this was the case in the terminals studied [6]. They reported considerable levels of work-related ill-health, that were not reflected by routinely collected data. This also demonstrated the presence of a substantial gap between the perceptions of company safety management about their arrangements for safety and health and 
outcomes in container terminals and those of workers who experienced them [5].

Supported by extensive interview data, the research further showed:

- Comparatively worse OSH arrangements and outcomes were experienced by contract workers involved in quay-side and transport activities especially in terminals in the poor country.

- OSH arrangements were dominated by behaviour-based approaches, focusing primarily on safety, that are disliked and distrusted by workers.

- Comparatively high levels of ill-health arising from psychosocial and ergonomic causes were experienced by workers and associated with changing patterns of work organisation and work intensification.

- The presence of contract workers in terminals was increasing. In the terminals in the low-income county they were the largest proportion of the labour force.

- Participative arrangements for OSH, including worker health and safety representatives were weakly developed in terminals in the low-income country and contract workers especially, had little or no voice in arrangements for their safety or health.

- Arrangements for effective representation on OSH were subject to challenges everywhere however, and examples of them working well were exceptional rather than the norm even in countries with histories of strong regulation and trade union presence in ports.

- Regulatory inspection of container terminals varied considerably by location. Overall, it was limited and especially in the low-income country where there were also significant concerns about regulatory capture.

As previously reported, experience of poor health outcomes was also associated with high levels of poor safety outcomes [6].

\section{Determinants of practice}

These findings beg questions concerning what determines the approach to OSH in the terminals of the GNT operators, and in this respect the study highlights tensions between the preferred strategies of these operators and host country contexts. In this section the influence of three key sets of determinants are explored. They are:

- the nature of governance and management strategies that influenced the measures on safety, health and welfare adopted by the terminal companies.

- their position within wider corporate business and management strategies; and

- determinants associated with economic, regulatory and labour relations contexts, found in the countries in which terminals were located.

They are illustrated graphically in Fig. 1 and explored in the next two subsections, the first of which considers corporate influence, while the second explores the effects of national determinants.

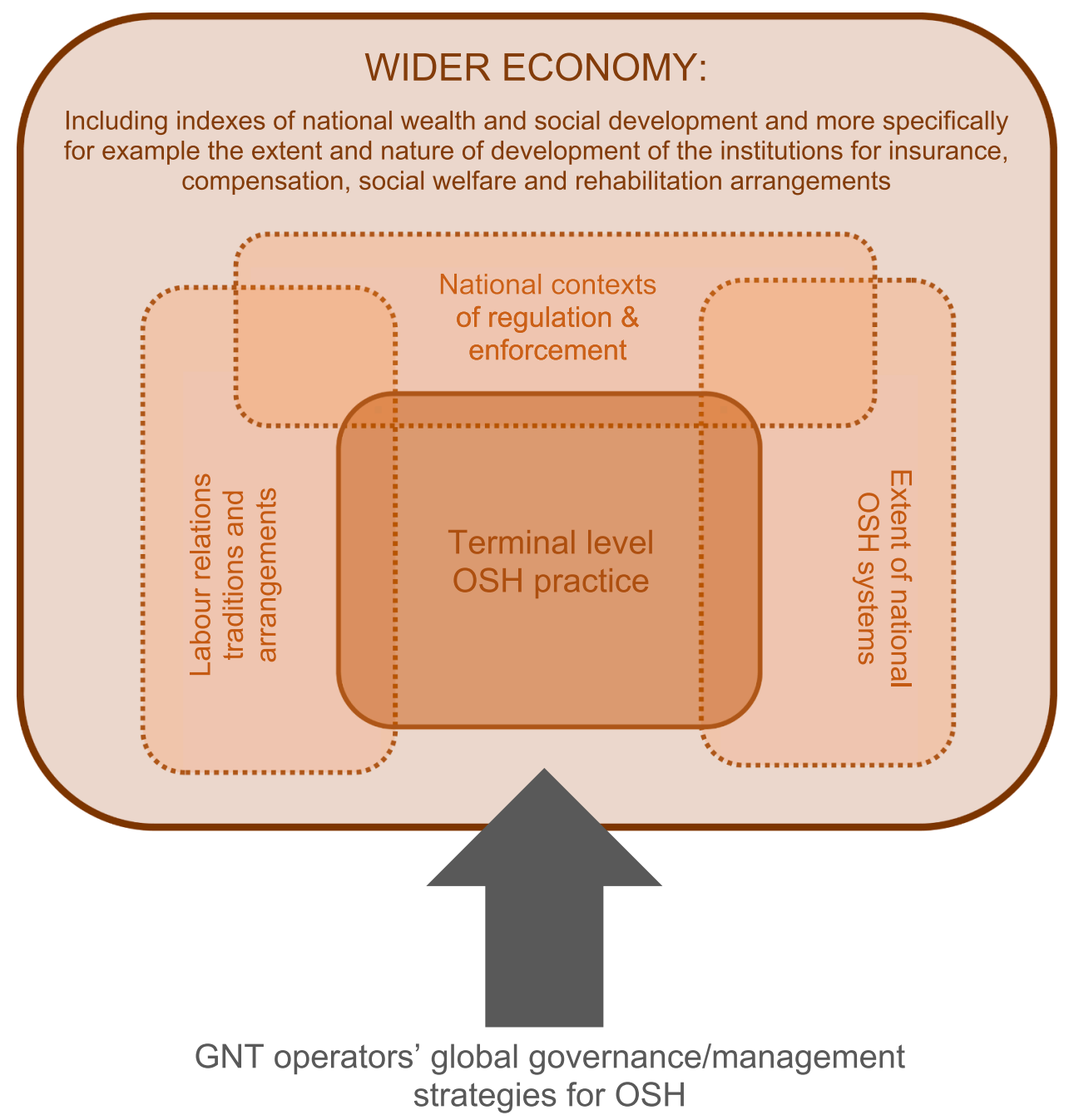

Fig. 1. The influence of context. 
Corporate governance and management strategies on OSH and their position within wider corporate strategies: The preferred corporate strategy on OSH arrangements was typical of those adopted by large multinational organisations. It owed more to voluntary international standards of good practice in OSH management - such as those promulgated by the International Standards Organisation (ISO), or marketed by high-end consultancies, and to good professional practice in high risk industries (such as was seen, for example, in an emphasis on critical incident reporting) - than it did to either national regulation or negotiated compromise with organised labour. Similarities between the GNT operators concerning corporate leadership on $\mathrm{OSH}$, zero accident tolerance, claims for OSH as a core business value, OSH performance indicators and accountability for OSH at all levels, lending support for the embedding of a 'safety culture' in that of corporate organisational culture more widely featured prominently in the corporate rhetoric of all these organisations [5]. But what they achieved in the terminals they operated varied by country [4-6].

Our analysis of data from interviews with managers with responsibility for OSH at corporate level suggests that GNTs behaved in ways similar to those described in the literature on human resource management (HRM) practices among multinational companies. That is, broadly speaking they were largely geocentric or regio-centric in their business approach [13] and this was reflected in their preferred approach to OSH. At the same time, the need to balance a number of overlapping local, national and international influences [14] in managing OSH in their 'business units' (the terminals), necessitated hybrid strategies, such as are also described in relation to HRM practices [15, 16]. They were constrained in the choices they could make for reasons not dissimilar to those suggested by Harzing and Pinnington [17]. This suggests their corporate OSH strategies, like those on HRM, reflected: a) the dominant international practice regarded as most beneficial to the organisation; b) the international character of the industry and the nature of its activity; and c) the market competition in which they functioned, while at the same time having regard to 'host country effects', to which they were obliged to respond, in order to conduct their business at these locations $[18,19]$.

The international HRM research literature also suggests that, in practice, MNCs may exert more centralised control over their business units located in developing economies - this was also the aspiration of the GNTs in the present study. Indeed, senior OSH managers interviewed at corporate level indicated a marked preference for developing OSH strategies in their terminals situated in such economies, believing they achieved better results when less constrained by embedded regulatory and labour relations institutions and practice.

But the HRM literature further concludes that how resources are managed in a subsidiary is partly shaped by local isomorphism reflective of the regulatory, labour relations, cognitive and normative profile of a host country $[16,20,21]$, causing the corporate leadership to often confront 'think global, act local' paradoxes in their undertakings [14]. Whitley [22], has argued that the scope for MNCs to introduce their own policies and practices is influenced by the degree and embeddedness of national regulation, with such originality being easier in 'less actively regulated business and employment relations contexts'. In a similar vein, Rosenzweig and Nohria [23] have noted how host country regulatory frameworks, the role of trade unions, and other institutional factors can be forces encouraging MNCs to localise human resource policies and practices [24]. Again, these influences were strongly evident in relation to the OSH management strategies of the GNT operators in the present study, and were especially prominent in relation to OSH activities in terminals in advanced market economies, as is reported in greater detail in the previously published comparative analysis between terminals located in a high income country and those from a low to middle income country [8].

National determinants: In as far as they apply directly to the arrangements for health and safety in the workplaces in the study, regulation and regulatory enforcement are the most tangible measures of national determinants of OSH practice.

All countries in which the terminals were situated had regulatory measures covering OSH in dock-work in place, as well as inspectorates to ensure the compliance of duty-holders. However, the measures themselves varied between countries, as did the resources, and extent and practice of regulatory inspection. Indeed, at global level, senior personnel with responsibility for $\mathrm{OSH}$ in the terminal operating companies referred to the operations of the company business units being located in 'heavily' or 'lightly' regulated countries. And as noted above, they expressed a preference for the latter, similar to that described in the literature on the HRM strategies of MNCs.

There were similarities in the orientation of the national regulatory provisions on $\mathrm{OSH}$ among high-income countries in the study. In keeping with global standards such as those found in ILO Convention 155 on safety and health, they could be described as principle and processbased requirements, which imposed duties, normally on employers, to manage health and safety systematically, with competent advice, having regard to the nature of the risks of the establishment and the work undertaken there and to consult with their workers and their representatives on these matters. Such broad-based statutory requirements were often supplemented by more specific regulations that applied to (aspects of) dock-work, which were more prescriptive in nature and which had been developed through national processes for delegated legislation. Generally, such prescriptive measures were increasingly subject to repeal, as deregulatory strategies aimed at creating conditions for economic growth and competitiveness were more widely deployed. However, there was variation between countries in the extent to which this had occurred. The regulatory provisions were often further supported with Codes of Practice and Guidance Notes covering some operational activities in the terminals with greater or more practical detail.

In contrast, although in the low-middle income country in which terminals were also situated, at national policies encouraged more principle and process-based approaches, regulatory provisions covering dock-work were still of the prescriptive type. A specific set of provisions addressed dock-work and also determined inspection activities, beyond which, as is further discussed below, regulatory inspectors did not feel empowered to act.

Regulatory influence is an element of the wider national 'health and safety system' which influences the nature of workplace practices and their outcomes in all countries [25]. Other elements of such national systems include, for example: support provided by national institutions for $\mathrm{OSH}$ education, research, training and information dissemination; provision of OSH services; national systems covering arrangements for compensation, rehabilitation and return to work, including the legal and social welfare systems involved. Further included are arrangements made by employers' organisations and trade unions, to support their members on health and safety matters; and those of insurance associations; public advice centres and information services; and so on. Such arrangements do not act in isolation however, and are part of wider systems for economic, health and social welfare, and the institutional actors and processes involved in them.

This interplay is represented in Fig. 1. It places workplace health and safety practice within the terminals at the centre of a constellation of influences. It demonstrates how the effects of corporate governance and management influences acting directly upon the terminals (represented by the broad arrow at the base of the diagram), in the ways described in this paper, are mediated by the influence of national context. Outcomes in relation to practice are therefore moderated by this influence and vary by location according to the strength of this effect.

This was clearly demonstrated in the findings of the research. These have been detailed in other publications $[4-6,8]$. They indicate that while companies implement a set of procedures and practices for safety management in their terminal operations, these measures are of a particular character. They begin with corporate 'safety leadership' governance strategies with an objective of achieving 'zero harm' in company safety performance. Having first addressed 'safe place' 
approaches in terminal design, which aim essentially to remove human work activities from the vicinity of operating machinery, this theme is continued with adoption of largely behaviour-orientated features of safety management in the systems in place in the terminals, along with the promotion of a 'safety culture' across all the global operators' business units. The findings of this study demonstrate that this results in approaches to safety, which generally overlook work-related health and welfare issues, tend to assume a common interest in company values and provide only limited institutional representation of autonomous workers' interests $[5,6]$. In these ways the approach is different to that found in principle and process based regulatory requirements on systematic OSH management that apply in the advanced market economies - seen especially for example in relation to the form and extent of worker participation advocated. It is also an approach that has been strongly contested by trade unions in these countries [27]. In addition, such an orientation is some way removed from that of global standards such as those adopted in International Labour Organization (ILO) Conventions and guidance on OSH management which share the same principle and process based approaches and advocate representative forms of participation in systematic OSH management [26].

Such ways of conceptualising the governance of workplace safety however, fit well with the approaches to organising work and employment adopted by corporate leaders and managers in the industry. A focus on changing workers' behaviour neither questions the basis of managerialist thinking, nor its assumptions concerning the unitary form of organisation culture and shared company values it promotes. Nor does it require critical examination of decisions on finance, on the structure, organisation and operation of work or the way in which business is conducted - and it does not accept a connection between these matters and the health, safety and welfare of workers. Yet, as the findings from the present study show, from the standpoint of the workers in the terminals, such features do have negative impacts upon their health and safety and welfare. Moreover, there is a wealth of research that shows that these structural, organisational and business features of modern corporate operation have similar effects in other sectors too (for example [28,29]). These other studies indicate such organisational structures and procedures are both unable to deliver the necessary controls to prevent every day harm to workers caused by the way work is organised, as well as being implicated among the causes of high-profile events such as process safety disasters which result in major harm to workers, hardware, the public and the environment. OSH governance and management strategies that ignore this can therefore expect to achieve only limited results in terms of the improvement of the health, safety and welfare of workers (see for example Quinlan on mining [30]; Sampson et al. on shipping [31]; Frick on other sectors [32]); and which all suffer from the same contradictions.

When they are applied in terminals situated in different economic, regulatory and labour relations contexts, the findings of the present study suggest it is the moderating effects of these contexts that help determine differences in the nature and experience of health and safety practice. There is support for this argument, not only in the HRM literature, but also in literature concerning governance and regulation. In particular, this literature suggests that positive outcomes will also be influenced by their institutional (including regulatory) contexts. For example, Short and Toffel (2010) have argued that even where selfregulatory approaches are favoured, organisations are more likely to comply with them 'when they. are subject to heavy regulatory surveillance' [33] Other more critical regulatory studies suggest this to be even more the case where such organisations also face meaningful threats of legal sanctions or reputational damage [34]. Such findings are further linked to current theorising in regulatory studies which argues for more 'responsive' and 'smarter' regulation [35,36]. That is, for forms of regulation and the means with which to seek and determine compliance with them that can bridge the gap between the state and the market by more effectively harnessing intermediary players and processes (including those of trade unions and labour relations) and acting in reflexive ways to promote various types of regulated self-regulation [37, 38].

\section{Illustrating the effects of context on OSH experiences}

The present research has produced some empirical evidence of these effects. It is summarised this graphically in Fig. 2. As detailed in the Methods section, combined composite measures of health and safety experiences in the terminals were plotted against contextual measures describing prevailing conditions in relation to levels of outsourcing and unionisation, degree of devolution of port ownership and maturity of OSH governance. This is acknowledged to be a crude approach, providing only a very broad approximation of the context in which the case study terminals operated. Nevertheless, Fig. 2 supports what perhaps we might anticipate from the account in previous paragraphs. That is - the poorest OSH conditions are likely to be experienced in terminals in poorer countries, where regulatory infrastructures are weak, as is the influence of organised labour, and economies are relatively underdeveloped, and in part because of this, national economic policies are politically supportive of opportunities for inward investment. This is obviously even more likely to be so where such opportunities are combined with improvements in logistics that determine the flow of goods, and potentially enhance the country's role in global trade.

Not only were there differences between regulation and regulatory enforcement apparent between the high- and low-income countries, but there were also marked differences in labour relations contexts described in detail in a previous paper concerning two of the countries in the study [8]. The nature of these differences and their historical and current labour relations trajectories are sufficiently substantial and detailed to warrant further accounts in their own right, but for the purpose of the present paper, two features are worthy of note. The first is that the strongest associations between the presence of these contextual determinants and workers' experiences of OSH practice and performance were between terminals situated in advanced market economies (where there were better experiences) and terminals in the poor country - where experiences were worse. Second, it was workers in terminals situated the European country which had the most highly regulated forms of dock-work found among all of the economies we studied, and which also had the strongest forms of organised labour still present in dock-work, who scored most favourably in terms of the composite scores for their health, safety, welfare and their satisfaction with management arrangements [4]. Thus, here again expression of what might be anticipated from the detailed qualitative findings is supported by the graphic representation of the quantitative analysis presented in Fig. 2.

\section{Conclusions}

At a recent international conference organised to promote an international campaign to spread a corporate culture of zero tolerance of fatal accidents, there were several presentations concerning safety and health arrangements in container terminals operated by large global network companies in ports situated in the host country. Two of the terminals to which the speakers' presentations referred - and in which they held senior positions with responsibility for safety and health management had been among those included in this study, from which detailed field data had been obtained from managers, workers and workers' representatives concerning their perceptions and experiences of the operation of the same arrangements. It was therefore surprising that these presenters described their systems for managing safety and health in a manner that bore little relation to the empirical findings of the analysis presented here. According to them, the arrangements for safety and health in these terminals were 'state of the art' and fit for purpose. They claimed they were based on the same 'vision' of zero tolerance of fatal accidents as that espoused by the conference organisers and their arrangements to achieve this, they further claimed, followed a broadly similar pattern to the recommendations found in the global campaign 


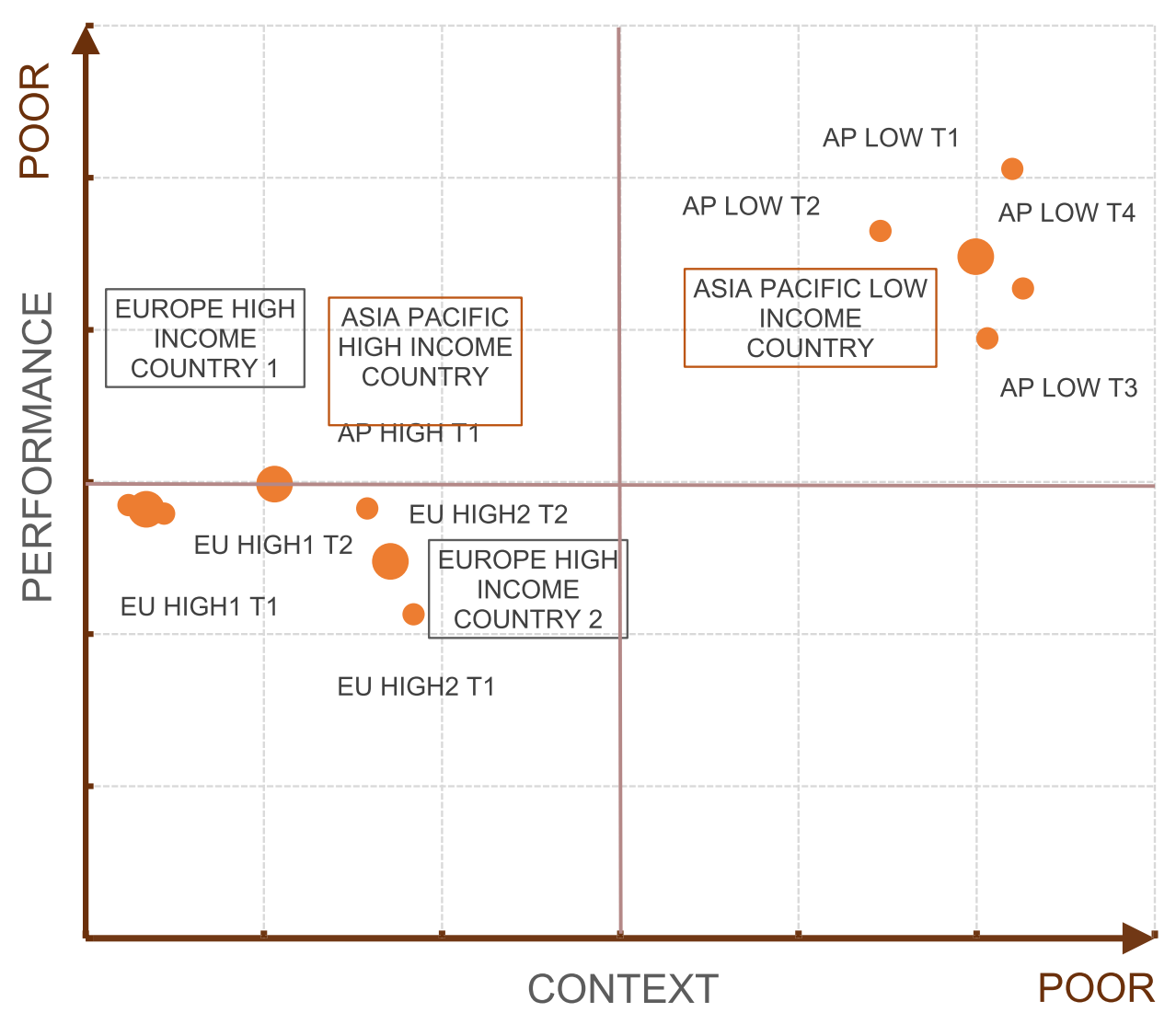

Key:

EU HIGH1 T1 - EU High Income Country 1 Terminal 1

EU HIGH1 T2 - EU High Income Country 1 Terminal 2

EU HIGH2 T1 - EU High Income Country 2 Terminal 1

EU HIGH2 T2 - EU High Income Country 2 Terminal 2

AP HIGH T1 - Asia Pacific High Income Country Terminal 1

AP LOW T1 - Asia Pacific Low Income Country Terminal 1

AP LOW T2 - Asia Pacific Low Income Country Terminal 2

AP LOW T3 - Asia Pacific Low Income Country Terminal 3

AP LOW T4 - Asia Pacific Low Income Country Terminal 4

Fig. 2. Context and performance by terminal.

behind the conference. They provided leadership on safety and health, and had identified and assessed risks at the terminals as well as putting in place appropriate means to control them through a systematic approach to ensuring safety in the terminal workplaces and plant, and in the behaviour of the workers, whether they were employed directly or by contractors. They stressed their focus on building a competent workforce through training and certification, building knowledge and skills, awareness, information flow, monitoring, internal control and surveillance, and everyone's commitment and continuous improvement. The methods they used to monitor the success of this approach in helping to build a strong and participative prevention culture at the workplace, which they claimed even extended to outreach activities supporting better risk awareness among communities beyond the terminal gates.

As outlined in this paper, the findings of the present study stand in marked contrast to such claims. In the same and other terminals in the low-income country studied, our results demonstrated poor indicators of both the arrangements for safety, health and welfare and the workers' experience of the outcomes. Indeed, comparison with terminals operated by the same companies in high-income countries indicated that they were the worst performers on virtually all the indicators we had used to measure safety, health and welfare arrangements and performance. Far from demonstrating effective corporate arrangements for safety and health management, operationalised at the workplace level, they indicated the existence of a substantial gap between these arrangements and the every-day experiences of workers. In particular, they showed that in the pursuit of production and cost efficiencies that are among corporate priorities for successful business in this highly competitive sector, the company and terminal level arrangements took little account of the health and welfare consequences of ways in which work and employment were organised in the terminals. Workers regarded the arrangements made for health and safety by the terminal management as wholly inadequate. The focus of the arrangements on 'safe person' strategies was perceived to threaten their security of employment, while at the same time the arrangements failed to address the health and welfare concerns they felt existed as a result of the organisation of their work and their employment, and they were divisive in their application between directly and indirectly employed workers. Indeed, the prominent use of contractors militated against the likelihood of a unified organisational culture. As Schein [39] argues, organisational unity is among the prerequisites for this. Efforts of terminal managers to achieve such unity were limited (as detailed previously [5]) and had at best met with only limited success in the terminals in the low to middle income country. 
A collective voice on health and safety was also not supported by the terminal management, arrangements made for the direct participation of workers led to further feelings of fear concerning job security, and promoted a lack of trust among these workers for their employers. Moreover, arrangements for consultation with contract workers were virtually non-existent. Yet, it was in these terminals and others in the low-income country especially, that the indirectly employed workforce, which was a majority of terminal workers, experienced proportionally the greatest risks to their safety and health and the poorest provision for their welfare.

This point is made not solely to dispute the impression conveyed by corporate actors concerning their safety management practices, but more than this, to demonstrate that the significant differences observed between workers' experiences in terminals located in different countries can be related to their national contexts and the determinants of health and safety arrangements, practices and outcomes that are found in these contexts. In particular, the findings show that regulatory and labour relations factors are associated with marked differences in experiences of safety, health and welfare between terminals in different countries in the study. This is not new. It has been demonstrated many times in many sectors and in many countries in the course of history and is among the fundamental reasons for the long-standing interest of the state in regulating safety and health, as well as the equally long-standing interest of organised labour in ensuring workers have an effective voice in this process. However, in our study, neither regulation nor the means of compliance or arrangements made to represent workers' interests were entirely effective anywhere. It is therefore disturbing that recent changes in global organisational arrangements for safety and health have not focused in this direction. Political and economic policies driving trade and production have striven to remove what have been regarded as 'burdens' on business freedoms. States have frequently withdrawn from a regulatory role, or failed to adopt one, while in the face of new freedoms thus granted to capital, institutions of organised labour have also declined globally and become less effective in supporting workers' collective voice. In their place, we have exhortations from global safety and health institutions, for greater voluntary engagement from businesses with the safety and health of workers. ${ }^{1}$

These exhortations embrace the goals of safety 'leadership', 'culture', 'awareness' 'commitment', and so on, as elements of unitary management control of work and employment, while at the same time creating considerable freedoms to enable corporate organisations to achieve them according to 'the way we do things round here.' And all this with the additional belief that they contribute to the productivity and cost effectiveness of the organisation. Such freedoms are, however, not extended to the workers who function in workplaces often at considerable remoteness in geographical, cultural, conceptual and even business terms from the corporate centre. Instead, these workers are subjected to highly prescriptive regimes focusing, often in a punitive way, upon the surveillance of behaviour modification regimes that, in practice, as this study and the literature demonstrate, may threaten job security and promote mistrust and a divisive culture within workplaces, while as this study has also shown, failing to address the workers' own perceptions of their safety, health and welfare concerns.

These are deeply disturbing developments that are all the more so when they are also given prominence in the policies of global organisations which exist supposedly to promote better safety and health standards for workers. The evangelist approach to improving safety and health currently promoted, for example, by the International Social Security Association (ISSA), and endorsed by the ILO, is orientated towards persuading corporate organisations to adopt a safety orientated

\footnotetext{
${ }^{1}$ For example, the conference to which we alluded at the beginning of this section was one of a series jointly supported by the International Social Security Association (ISSA) in which the corporate adoption of a so-called 'Vision Zero' approach to OSH is heavily promoted.
}

approach among their core corporate values and aim to eliminate fatal accidents. It is replete with easy to assimilate strap-lines promoting safety management techniques embedded in 'golden rules' that claim to embrace health, safety and welfare, and support 'worker participation' in this process, but which are silent on the role of either the collective representation and consultation with workers on such matters or that of regulatory inspection. As critics of these initiatives have made clear, while they may be well intended, they are largely empty of content and allow corporate interests to adopt their rhetoric without challenging any of the fundamental strategies with which they operate their businesses. In the words of Sherratt [40], '... [they] aim to operate within the existing environment, seeking engagement of the workforce without addressing problems of practice.'.

An identity of interest between employers and their workers is assumed and reflected in the flag waving, song contests and other promotional activities that characterise campaigns promoting these aims. However, the identity of the interests thus assumed are those with corporate organisational values rather with than the interests of workers that decades of study of the sociology of work have marked out as often quite different to those of corporate management (see for example [41-44]). As the present study shows, the consequences of this are that workers feel their concerns, especially those about their health and well-being, are ignored by corporate arrangements. A further consequence, already noted by others [44], is that workers are deeply mistrustful of them, perceiving managerial priorities to continue to reflect concerns around production and profits rather than their well-being - a finding also noted by other researchers who report lower scores from workers than managers when rating management safety priorities in such initiatives $[45,46]$.

The key message, therefore, is not how terminals compare in the ways they operationalise their approaches to safety management, but rather the impact of context on this comparison. The findings of this study indicate that corporate operators, have the capacity to put in place strategies addressing $\mathrm{OSH}$ that can be effective in managing safety, health and welfare in their business units globally, but, in ways similar to those that research on HRM practices of MNCs has shown to be widely practiced, they generally only do so when the contexts in which these business units are situated oblige them to. It is therefore not the 'zerovision' rhetoric that drives positive outcomes for workers' safety, health and well-being effectively, but rather, the influence of regulatory and labour relations contexts on the ways in which such rhetoric is converted into practice. In this respect the analysis of empirical evidence suggests that in the absence of strong and effectively enforced regulation and a more even distribution of the balance of power between business and labour, that supports a more effective voice on OSH for the latter, global operating companies continue to prioritise the productivity of their terminal operations over the introduction of more effective strategies to manage their consequences for the safety, health and welfare of the workers employed in their delivery.

\section{CRediT authorship contribution statement}

David Walters Conceptualization, Methodology, Writing- original draft preparation. Visualization, Investigation, Supervision, Writing review \& editing. Emma Wadsworth Software Data curation, Methodology, Visualization, Investigation, Software, Validation, Writing review \& editing.

\section{Acknowledgements}

This research was funded by the Institution of Occupational Safety and Health (IOSH) and the International Transport Workers' Federation (ITF). 


\section{Declaration of conflicting interests}

The authors declare that there is no conflict of interest.

\section{References}

[1] E. Bonacich, J. Wilson, Getting the Goods: Ports, Labor, and the Logistics Revolution, Cornell University Press, New York, NY, 2008.

[2] J. Rodrigue, T. Notteboom, Global networks in the container terminal operating industry. Part 1: how global are global operators? Port. Technol. Int. 49 (2011) 10-14.

[3] M. Sisson, Automation and safety on container terminals: accidents and injuries on the quayside have reduced dramatically over the past 50 years, so how can we continue this trend into the future? Port. Technol. Int. 47 (2012) 70-73.

[4] D. Walters E. Wadsworth, Experiences of arrangements for health, safety and welfare in the global container terminal industry. Leicester, UK: International Institution of Occupational Safety and Health; 2016. 〈http://www.iosh.co. $\mathrm{uk} /$ /media/Documents/Books\%20and\%20resources/Published\%20research /Global\%20container\%20terminal\%20industry.pdf?la=en $\rangle$. Accessed May 20, 2019.

[5] D. Walters, E. Wadsworth, Arrangements for workers' safety and health in container terminals: Corporate core values and concrete practice, Econ Ind Democracy (2020), https://doi.org/10.1177/0143831X19893767.2.

[6] D. Walters, E. Wadsworth, S. Bhattacharya, What about the workers? Experiences of arrangements for safety and health in global container terminals, Safety Sci 121 (2020) 474-484.

[7] C. Van Stolk, L. Staetsky, E. Hassan, C. Kim, Factors associated with effective management of occupational safety and health: an empirical analysis, European Agency for Safety and Health at Work, Bilbao, Spain, 2012. Accessed May 20, 2019, 〈https://osha.europa.eu/en/tools-and-publications/publications/reports/ management-of-occupational-safety-and-health-analysis-of-data-from-the-esener $>$.

[8] E. Wadsworth, S. Bhattacharya, D. Walters, Representing workers on arrangements for occupational health and safety in a global industry: Dockworkers experiences in two countries, Policy and Practice in Health and Safety 13 (2) (2015) 87-107.

[9] B. Fabiano, F. Currò, A. Reverberi, R. Pastorino, Port safety and the container revolution: a statistical study on human factor and occupational accidents over the long period, Saf. Sci. 48 (8) (2010) 980-990.

[10] M. Quinlan, P. Bohle, Under pressure, out of control or home alone? reviewing research and policy debates on the OSH effects of outsourcing and home-based work, Int J. Health Serv. 38 (3) (2008) 489-525.

[11] M. Quinlan, C. Mayhew, P. Bohle, The global expansion of precarious employment, work disorganisation, and consequences for occupational health: a review of recent research, Int J. Health Serv. 31 (2) (2001) 335-414.

[12] D. Weil, The Fissured Workplace: Why Work Became so Bad For so Many and What Can Be Done to Improve It, Harvard University Press, Boston, MA, 2014.

[13] D. Heenan, H. Perlmutter, Multinational Organization Development: A Social Architectural Perspective, Addison-Wesley, London, UK, 1979.

[14] K. Sisson , Reflections on the papers of the multinational companies and HRM: Between globalisation and national business systems. Conference, De Montfort University Graduate School of Business, 12th-14th July 2001.

[15] P. Dowling, D. Welch, R. Schuler, International Human Resource Management: Managing People in a Multinational Context, third ed.,, South-Western College, London, UK, 1999.

[16] M. Tayeb, Transfer of HRM practices across cultures: an American company in Scotland, Int J. Hum. Resour. Manag. 9 (2) (1998) 332-358.

[17] A. Harzing, A. Pinnington, International Human Resource Management, fourth ed.,, Sage, London, UK, 2015.

[18] I. Bjorkman, K. Stahl, E. Vaara, Cross cultural differences and capability transfer in cross-border acquisitions: the mediating roles of capability complementarity, absorptive capacity and social integration, J. Int. Bus. Stud. 38 (4) (2007) 658-672.

[19] C. Brewster, Globalising HR . London, UK: CIPD Publishing; 2002.

[20] P. DiMaggio, W. Powell, The iron cage revisited: Institutional isomorphism and collective rationality in organizational fields, Am. Sociol. Rev. 48 (2) (1983) $147-160$.
[21] T. Kostova, K. Roth, Adoption of an organizational practice by subsidiaries of multinational corporations: institutional and relational effects, Acad. Manag. J. 45 (1) (2002) 215-233.

[22] R. Whitley, How and why are intern ational firms different? the consequences of cross-border managerial coordination for firm characteristics and behaviour, in: G. Morgan, P. Kristensen, R. Whitley (Eds.), The Multinational Firm: Organizing Across Institutional and National Divides, University Press, Oxford, Uk, 2001, pp. 27-68.

[23] P. Rosenzweig, N. Nohria, Influences on human resource management practices in multinational corporations, J. Int. Bus. Stud. 25 (2) (1994) 229-251.

[24] A. Ferner, The underpinning of bureaucratic control systems: HRM in European multinationals, J. Manag. Stud. 37 (4) (2000) 521-540.

[25] D. Walters, E. Wadsworth, Contexts and determinants of the management of occupational safety and health in European workplaces, Policy Pract. Health Saf. 12 (2) (2014) 109-130.

[26] International Labour Organization (ILO), Guidelines on occupational safety and health management system, second ed.,, ILO,, Geneva, Switzerland, 2009. (htt p://www.ilo.org/safework/info/standards-and-instruments/WCMS_107727/lan g-en/index.htm $\rangle$.

[27] A. Hopkins, What are we to make of safe behaviour programs? Saf. Sci. 44 (2005) 583-597.

[28] J. Le Coze, Disasters and organisations: from lessons learnt to theorising, Saf. Sci. 46 (2008) 132-149.

[29] C. From Woolfson, Piper alpha to deepwater horizon, in: T. Nichols, D. Walters (Eds.), Safety or Profit? International Studies in Governance, Change and the Work Environment, Baywood, New York, 2013.

[30] M. Quinlan, Ten Pathways to Death and Disaster: Learning from Fatal Incidents in Mines and Other High Hazard Workplaces, The Federation Press, Annandale, Australia, 2014.

[31] H. Sampson, N. Turgo, I. Acejo, N. Ellis, L. Tang, Between a rock and a hard place': the implications of lost autonomy and trust for professionals at sea, Work Employ. Soc. 33 (2019) 648-665, https://doi.org/10.1177/0950017018821284.

[32] K. Frick, Worker influence on voluntary OHS management systems - a review of its ends and means, Saf. Sci. 49 (7) (2011) 974-987.

[33] J. Short, M. Toffel, Making self-regulation more than merely symbolic: the critical role of the legal environment, Adm. Sci. Quart. 55 (3) (2010) 361-396.

[34] S. Tombs, D. Whyte, The myths and realities of deterrence in workplace safety regulation, Brit. J. Criminol. 53 (5) (2013) 746-763.

[35] I. Ayres, J. Braithwaite, Responsive Regulation: Transcending the Deregulation Debate, Oxford University Press, New York, NY, 1992.

[36] N. Gunningham, D. Sinclair, Regulatory pluralism: designing policy mixes for environmental protection, Law Policy 21 (1) (1999) 49-76.

[37] C. Estlund, Re-governing the Workplace: From Self-Regulation to Co-Regulation, Yale University Press, New Haven, CT, 2010.

[38] G. Teubner, After legal instrumentalism? strategic models of post-regulatory law, in: G. Teubner (Ed.), Dilemmas of Law in the Welfare State, De Gruyter, Berlin, Germany, 1986, pp. 299-326.

[39] E. Schein, Organizational Culture and Leadership, fifth ed.,, Wiley, 2004.

[40] F. Sherratt, Exploring 'Zero target' safety programmes in the UK construction industry, Constr. Manag. Econ. 32 (7-8) (2014) 737-748.

[41] T. Nichols, P. Armstrong, Safety or Profit? Falling Wall Press, Bristol, UK, 1973.

[42] T. Nichols, The Sociology of Industrial Injury, Mansell, London, UK, 1997.

[43] J. Eakin, Towards a 'standpoint' perspective: health and safety in small workplaces from the perspective of the workers, Policy Pract. Health Saf. 8 (2) (2010) $113-127$.

[44] G. Gray, The responsibilization strategy of health and safety: neo-liberalism and the reconfiguration of individual responsibility for risk, Brit. J. Criminol. 49 (3) (2009) 326-342.

[45] S. Dekker, Zero vision: enlightenment and new religion, Policy Pract. Health Saf. 15 (2) (2017) 101-107.

[46] G. Zwetsloot, M. Aaltonen, J. Wybo, J. Saari, P. Kines, Op De Beeck R. The case for research into the zero-accident vision, Saf. Sci. 58 (2013) 41-48. 